\title{
Pathotypes of Colletotrichum sublineolum in Arkansas
}

\author{
J. W. Moore, Former Senior Graduate Assistant, M. Ditmore, Research Associate, and D. O. TeBeest, University \\ Professor, Department of Plant Pathology, University of Arkansas, Fayetteville 72701
}

\begin{abstract}
Moore, J. W., Ditmore, M., and TeBeest, D. O. 2008. Pathotypes of Colletotrichum sublineolum in Arkansas. Plant Dis. 92:1415-1420.

Sorghum anthracnose, caused by Colletotrichum sublineolum, is widely distributed in most grain sorghum-producing areas in Arkansas, and localized epidemics continue to occur across the state. The objectives of this research were to determine the number of pathotypes of $C$. sublineolum in Arkansas and to determine where these pathotypes are located within the state. Ninetyeight isolates were collected from research stations and production fields located in the Delta region of Arkansas from 2003 through 2005 and were tested for virulence to eight differential grain sorghum breeding lines. Of these, 11 isolates produced conflicting and unreliable results and were excluded from further analysis. Among the remaining 87 isolates, 13 pathotypes were identified. Eleven of these pathotypes were previously unreported, with $53 \%$ of the isolates consisting of pathotype 9. Pathotype 9 was distinguished from all other pathotypes by its virulence to all eight differential lines. Pathotype diversity appeared to be more closely associated with the year than with the locations where isolates were collected. Although all host differential lines were susceptible to at least $50 \%$ of the isolates evaluated, inbred lines SC326-6, TAM428, and TX2536 were susceptible to more than $90 \%$ of the 87 isolates evaluated. These results showed that the $C$. sublineolum populations in Arkansas are diverse based on the comparisons of pathogenicity to previously published host differentials, and it appears that these field populations varied from year to year.
\end{abstract}

Additional keywords: anthracnose severity, pathotype determination

Sorghum anthracnose, caused by Colletotrichum sublineolum (Henn.) in Kabat \& Bubak (formerly C. graminicola (Ces.) G.W. Wilson), is an important disease in nearly all grain sorghum (Sorghum bicolor) production regions of the world. This disease infects and damages leaves, stalks, peduncles, and panicles $(5,16,17)$ and causes estimated yield losses exceeding $50 \%$ on highly susceptible cultivars (6). Yield losses may be attributed to both reduced kernel number and size due to floret mortality, because Ngugi et al. (9) reported that sorghum anthracnose developed slowly before anthesis and increased rapidly during the grain-filling stage.

Before 1985, sorghum anthracnose was considered to be of minor importance in Arkansas; however, in 1985, C. sublineolum severely infected grain sorghum fields in southwest Arkansas, causing significant yield reductions (4). At that time, it was not known whether the outbreak was caused by abnormal environmental condi-

Corresponding author: D. O. TeBeest E-mail: dtebeest@uark.edu

Current address of J. W. Moore: Senior Station Superintendent, Cimarron Valley Research Station, Oklahoma State University, Perkins 74059.

Accepted for publication 6 June 2008.

doi:10.1094/PDIS-92-10-1415

(C) 2008 The American Phytopathological Society tions or whether the pathogen in this area had adapted and become more virulent than before (4). Since then, numerous studies have been conducted to evaluate the level of resistance in different sorghum hybrids to sorghum anthracnose (12).

It has been suggested that one of the most effective control strategies for sorghum anthracnose is disease resistance (13), and many of the inbred lines used in popular hybrids were developed for anthracnose resistance in areas of the southern United States (12). However, management of this disease through host resistance has often been unsuccessful because this pathogen is considered to be hypervariable $(1,2,10)$. Additionally, several pathotypes and haplotypes of this fungus have been reported $(1,2,4,11$, 14,15). Eight pathotypes of C. sublineolum have been reported among isolates collected in Georgia, Puerto Rico, and Texas. Pathotypes 7 and 8 were the most virulent on the sorghum differentials tested (2). Notably, pathotype 7 from Puerto Rico and pathotype 8 from Georgia were virulent on all sorghum differentials except SC41412E and BTX378, respectively (2). Similar experiments using the same set of sorghum differentials compared an Arkansas isolate with an isolate from the Brazos River Bottoms of Texas (4). Results from these studies indicated that the Arkansas isolate on breeding lines SC326-6 and BTX378 (4). In Georgia, nine C. sublineolum haplocaused more disease than the Texas isolate types were identified in a field where several seed companies tested their breeding lines for anthracnose resistance (11).

Although anthracnose is widely distributed in Arkansas, information is lacking on the number of pathotypes and their distribution within the state. Without reliable information on pathotypes, recommendations to Arkansas producers on which grain sorghum hybrids to plant are difficult, if not impossible, to develop. Therefore, the objectives of this research were to determine (i) the number of pathotypes of $C$. sublineolum in Arkansas and (ii) where these pathotypes exist within the state.

\section{MATERIALS AND METHODS}

Isolate collection, isolation, and storage. In 2003, 2004, and 2005, 98 C. sublineolum isolates in all were collected from production fields located in the major grain sorghum production areas within the state and from cultivar test plots at the University of Arkansas Pine Tree Branch Station near Colt, AR and at the University of Arkansas Lon Mann Cotton Research Station near Marianna, AR. Information for each isolate regarding the city, county, year, and sorghum hybrid from which each isolate was collected can be found in Table 1. Because anthracnose develops in patches within a field, leaf samples with characteristic anthracnose lesions were collected randomly from these foci in the field at sorghum maturity, placed in a plant press, and transported to the University of Arkansas for pathogen isolation.

Small sections of individual lesions $(0.5$ $\mathrm{cm}^{2}$ ) were collected from each leaf and immediately placed in sterile water for 1 min followed by a 2 -min soak in $1 \%$ sodium hypochlorite. After the lesions were disinfested, each was placed on Emerson yeast extract agar (YpSS) medium (4 $\mathrm{g}$ of yeast extract, $15 \mathrm{~g}$ of soluble starch, $1 \mathrm{~g}$ of $\mathrm{K}_{2} \mathrm{HPO}_{4}, 0.5 \mathrm{~g}$ of $\mathrm{MgSO}_{4}$, and $16 \mathrm{~g}$ of agar per liter), as described previously by $\mathrm{Li}$ (7), and placed in an incubator at $25^{\circ} \mathrm{C}$ under fluorescent lights (GE warm white brightstik 33 with a fluorescent light output of 725 lumens) with a 16-h photoperiod. Once these field cultures began to sporulate, a sterile loop was used to transfer spores into a 2-ml centrifuge tube containing $1 \mathrm{ml}$ of distilled water in order to dilute the spores. Approximately $20 \mu \mathrm{l}$ of the spore mixture was streaked onto $2 \%$ water agar medium (20 $\mathrm{g}$ of agar per liter of distilled water), then placed in an incubator at $25^{\circ} \mathrm{C}$ under fluorescent lights with a 16 -h photoperiod to promote spore ger- 
mination. After $48 \mathrm{~h}$, individual germinated spores were collected using a dissecting microscope and transferred to YpSS agar medium, then placed in an incubator at $25^{\circ} \mathrm{C}$ under fluorescent lights with a 16-h photoperiod to promote colony growth and sporulation.

After the single spore cultures started to sporulate, mycelium plus spores were harvested and placed into 2-ml sterile, cryule tubes (Wheaton, Millville, NJ) containing a cryopreservative solution (1:1 solution of $10 \%$ nonfat dry milk and $40 \%$ glycerol) for long-term storage. All single-spore cultures were stored in a cryofreezer $\left(-80^{\circ} \mathrm{C}\right)$.

Host differentials. Selected grain sorghum inbred lines, previously used to iden- tify pathotypes (2), were obtained from William L. Rooney, Texas A\&M University. Grain sorghum seed were planted in Jiffy-7 peat pellets (Hummert International, Earth City, MO) at a rate of one seed per peat pellet. Following germination, seedlings were allowed to grow to the one- to two-leaf stage before being transplanted to $25-\mathrm{cm}$ diameter plastic pots filled with loam, peat, and sand $(4: 4: 1, \mathrm{vol} / \mathrm{vol} / \mathrm{vol})$. Three sorghum seedlings were transplanted to each pot and placed in a greenhouse at 24 to $32^{\circ} \mathrm{C}$, with a photoperiod of $16 \mathrm{~h}$. In the absence of natural sunlight, quartz halogen lamps were used to supplement natural lighting for the duration of the experiment. All plants were fertilized with All Purpose
Plant Food (Miracle-Gro Products, Inc., Marysville, $\mathrm{OH})$ at 14 and 28 days after planting (DAP).

Inoculum preparation and inoculation. Single-spore isolates were grown on YpSS agar medium at $25^{\circ} \mathrm{C}$ under fluorescent lights with a 16-h photoperiod to promote sporulation. Inoculum was prepared by flooding 10-day-old cultures with $20 \mathrm{ml}$ of distilled water followed by filtering the conidial suspension through three layers of cheesecloth. The final spore concentration for each isolate was adjusted to approximately $1 \times 10^{6}$ spores $\mathrm{ml}^{-1}$ using a hemacytometer.

Approximately 40 to 45 DAP, the host differentials were inoculated with conidial

Table 1. Pathotype designation, origin, year of collection, and source hybrid for each of the Colletotrichum sublineolum isolates evaluated in this research

\begin{tabular}{|c|c|c|c|c|c|}
\hline \multirow[b]{2}{*}{ Isolate } & \multirow[b]{2}{*}{ Pathotype $^{y}$} & \multicolumn{2}{|c|}{ Origin } & \multirow[b]{2}{*}{ Year } & \multirow[b]{2}{*}{ Hybrid } \\
\hline & & Location, $\mathbf{A R}^{\mathbf{z}}$ & County & & \\
\hline AR551 & 11 & Forrest City & St. Francis & 2003 & Asgrow A571/Farmer's field \\
\hline AR552 & 10 & Forrest City & St. Francis & 2003 & Asgrow A571/Farmer's field \\
\hline AR553 & 11 & Forrest City & St. Francis & 2003 & Asgrow A571/Farmer's field \\
\hline AR555 & 14 & Forrest City & St. Francis & 2003 & Asgrow A571/Farmer's field \\
\hline AR556 & 11 & Forrest City & St. Francis & 2003 & Asgrow A571/Farmer's field \\
\hline AR558 & 10 & Marianna & Lee & 2003 & Dyna Gro X17F90 \\
\hline AR562 & 10 & Marianna & Lee & 2003 & Dyna Gro X17F90 \\
\hline AR564 & 10 & Marianna & Lee & 2003 & Dyna Gro X17F90 \\
\hline AR565 & 7 & Marianna & Lee & 2003 & Terral TV97H17 \\
\hline AR568 & 9 & Marianna & Lee & 2003 & Terral TV97H17 \\
\hline AR569 & 12 & Marianna & Lee & 2003 & Terral TV97H17 \\
\hline AR571 & 9 & Marianna & Lee & 2003 & DEKALB DKS54-00 \\
\hline AR572 & 9 & Marianna & Lee & 2003 & DEKALB DKS54-00 \\
\hline AR573 & 8 & Marianna & Lee & 2003 & DEKALB DKS54-00 \\
\hline AR575 & 17 & Marianna & Lee & 2003 & DEKALB DKS54-00 \\
\hline AR576 & 9 & Marianna & Lee & 2003 & Monsanto X234 \\
\hline AR577 & 8 & Marianna & Lee & 2003 & Monsanto X234 \\
\hline AR579 & 13 & Marianna & Lee & 2003 & Monsanto X234 \\
\hline AR580 & 8 & Marianna & Lee & 2003 & Monsanto X234 \\
\hline AR581 & 11 & Marianna & Lee & 2003 & Monsanto X234 \\
\hline AR583 & 7 & Marianna & Lee & 2003 & FFR 318 \\
\hline AR587 & 9 & Marianna & Lee & 2003 & FFR 318 \\
\hline AR588 & 8 & Pine Tree & St. Francis & 2003 & Dyna Gro 732B \\
\hline AR589 & 8 & Pine Tree & St. Francis & 2003 & Dyna Gro $732 B$ \\
\hline AR590 & 8 & Pine Tree & St. Francis & 2003 & Dyna Gro 732B \\
\hline AR592 & 8 & Pine Tree & St. Francis & 2003 & Dyna Gro $732 B$ \\
\hline AR594 & 7 & Pine Tree & St. Francis & 2003 & Triumph TR461 \\
\hline AR595 & 7 & Pine Tree & St. Francis & 2003 & Triumph TR461 \\
\hline AR597 & 9 & Pine Tree & St. Francis & 2003 & Triumph TR461 \\
\hline AR599 & 9 & Pine Tree & St. Francis & 2003 & Triumph TR461 \\
\hline AR600 & 7 & Pine Tree & St. Francis & 2003 & Triumph TR461 \\
\hline AR601 & 7 & Pine Tree & St. Francis & 2003 & Triumph TR459 \\
\hline AR603 & 9 & Pine Tree & St. Francis & 2003 & Triumph TR459 \\
\hline AR605 & 9 & Pine Tree & St. Francis & 2003 & Triumph TR459 \\
\hline AR606 & 9 & Pine Tree & St. Francis & 2003 & Triumph TR459 \\
\hline AR607 & 10 & Marianna & Lee & 2003 & Unknown/Field isolate \\
\hline AR612 & 10 & Marianna & Lee & 2003 & Dyna Gro X17F30 \\
\hline AR615 & 18 & Marianna & Lee & 2003 & Unknown/Field isolate \\
\hline AR623 & 9 & Marianna & Lee & 2004 & Terral TV9421 \\
\hline AR625 & 9 & Marianna & Lee & 2004 & Dyna Gro $780 \mathrm{~B}$ \\
\hline AR627 & 9 & Marianna & Lee & 2004 & FFR 322 \\
\hline AR628 & 9 & Marianna & Lee & 2004 & Terral TV96H81 \\
\hline AR634 & 9 & Marianna & Lee & 2004 & Pioneer 84G62 \\
\hline AR635 & 9 & Marianna & Lee & 2004 & Dyna Gro 780B \\
\hline AR646 & 9 & Marianna & Lee & 2004 & Dyna Gro 751B \\
\hline AR647 & 9 & Marianna & Lee & 2004 & Asgrow A571 \\
\hline
\end{tabular}

(continued on next page)

y Pathotype designation is based on the virulence pattern of each Arkansas isolate to a subset of inbred sorghum breeding lines SC326-6, SC414-12E, BTX378, TAM428, TX2536, SC328C, QL3 (India), and BTX398 as described by Cardwell et al. (2). Eleven isolates were designated as ? (= unknown) because different reactions were observed on some of the host differentials between repetitions.

${ }^{\mathrm{z}}$ All isolates collected at Marianna were isolated from plants grown on the Cotton Branch Research Station near Marianna, AR. Isolates collected at Pine Tree came from the Pine Tree Branch Research Station near Colt, AR. The remaining isolates were collected from producer fields located in the designated county. 
suspensions from each isolate using an airbrush sprayer with compressed air. Immediately following the inoculation, the plants were placed in a dew chamber at $25^{\circ} \mathrm{C}$ for $24 \mathrm{~h}$. After this 24 -h period, the plants were removed from the dew chamber and returned to the same greenhouse for the duration of the experiment.

Pathotype determination. Sorghum differentials were evaluated for lesion type reactions at 14 days after inoculation (DAI) as described by Cardwell et al. (2) and Dale et al. (4) using the following scale: resistant $(\mathrm{R})=$ very small lesions with no evidence of lesion expansion or increase in size; moderately resistant (MR) $=$ lesions larger $(1$ to $3 \mathrm{~mm})$, but not generally associated with sporulation or sig- nificant chlorosis; moderately susceptible $(\mathrm{MS})=$ lesions larger $(4$ to $6 \mathrm{~mm})$ and associated with chlorosis and some sign of sporulation on a few lesions; and susceptible $(\mathrm{S})=$ lesions generally large $(>6 \mathrm{~mm})$, with significant chlorosis and sporulation occurring on $>50 \%$ of the lesions. All R and MR lesion-type reactions were designated as (-) and all MS and $\mathrm{S}$ reactions were designated as $(+)$. These minuses $(-)$ and pluses $(+)$ were used to generate a virulence pattern for each isolate on all eight host differentials.

Anthracnose severity. In addition to the lesion-type reaction ratings, disease severity was determined for each sorghum host differential 14 DAI using a modified Horsfall-Barratt scale, where $0=$ none, $1=0$ to
$3 \%, 2=4$ to $6 \%, 3=7$ to $12 \%, 4=13$ to $25 \%, 5=26$ to $50 \%, 6=51$ to $75 \%, 7=76$ to $88 \%, 8=89$ to $94 \%, 9=95$ to $97 \%$, and $10=98$ to $100 \%$. Ratings were converted to the midpoint percentages before analysis.

Experimental design and data analysis. All experiments were designed as a split plot with $C$. sublineolum isolates as the main plot and the grain sorghum inbred lines as the split plot. Three plants of each sorghum breeding line were evaluated for each main plot treatment (isolate). Each plant represented a replication and all experiments were repeated once. The main plots consisted of 98 C. sublineolum isolates (Table 1) while the split plots consisted of eight grain sorghum inbred lines:

Table 1. (continued from preceding page)

\begin{tabular}{|c|c|c|c|c|c|}
\hline \multirow[b]{2}{*}{ Isolate } & \multirow[b]{2}{*}{ Pathotype $^{y}$} & \multicolumn{2}{|c|}{ Origin } & \multirow[b]{2}{*}{ Year } & \multirow[b]{2}{*}{ Hybrid } \\
\hline & & Location, $\mathbf{A R}^{\mathbf{z}}$ & County & & \\
\hline AR648 & 7 & Pine Tree & St. Francis & 2004 & Triumph TR82G \\
\hline AR659 & 9 & Pine Tree & St. Francis & 2004 & Asgrow A571 \\
\hline AR661 & 9 & Marianna & Lee & 2004 & Sorgh. Partners K72-J6 \\
\hline AR664 & 9 & Pine Tree & St. Francis & 2004 & Dyna Gro $780 \mathrm{~B}$ \\
\hline AR666 & 9 & Marianna & Lee & 2004 & Dyna Gro 751B \\
\hline AR668 & 9 & Pine Tree & St. Francis & 2004 & Unknown/Field isolate \\
\hline AR670 & 9 & Pine Tree & St. Francis & 2004 & Terral TV9421 \\
\hline AR672 & 7 & Pine Tree & St. Francis & 2004 & Dyna Gro 751B \\
\hline AR673 & 9 & Pine Tree & St. Francis & 2004 & Unknown/Field isolate \\
\hline AR675 & 8 & Pine Tree & St. Francis & 2004 & Terral TV9421 \\
\hline AR677 & 9 & Marianna & Lee & 2004 & Dyna Gro 751B \\
\hline AR683 & 9 & Marianna & Lee & 2004 & Asgrow A571 \\
\hline AR689 & 7 & Pine Tree & St. Francis & 2004 & Golden Acres 444E \\
\hline AR694 & 9 & Marianna & Lee & 2004 & Dyna Gro 751B \\
\hline AR699 & $?$ & Pine Tree & St. Francis & 2004 & Pioneer 84G62 \\
\hline AR727 & 9 & Marianna & Lee & 2004 & Dyna Gro 751B \\
\hline AR730 & 9 & Pine Tree & St. Francis & 2004 & DEKALB DKS53-11 \\
\hline AR733 & 9 & Marianna & Lee & 2004 & DEKALB DKS53-11 \\
\hline AR735 & 9 & Marianna & Lee & 2004 & Pioneer 84G62 \\
\hline AR776 & 9 & Pine Tree & St. Francis & 2004 & Golden Acres 444E \\
\hline AR777 & 9 & Pine Tree & St. Francis & 2004 & Triumph TR82G \\
\hline AR778 & 9 & W of Kelso & Desha & 2004 & Unknown/Farmer's field \\
\hline AR779 & 9 & W of Kelso & Desha & 2004 & Unknown/Farmer's field \\
\hline AR780 & $?$ & W of Kelso & Desha & 2004 & Unknown/Farmer's field \\
\hline AR781 & 9 & Near Backgate & Desha & 2004 & Unknown/Farmer's field \\
\hline AR783 & 9 & Near Backgate & Desha & 2004 & Unknown/Farmer's field \\
\hline AR786 & 7 & Near Backgate & Desha & 2004 & Unknown/Farmer's field \\
\hline AR787 & 9 & Near Backgate & Desha & 2004 & Unknown/Farmer's field \\
\hline AR793 & 9 & Near Backgate & Desha & 2004 & Unknown/Farmer's field \\
\hline AR797 & 9 & S of Marianna & Lee & 2004 & Unknown/Farmer's field \\
\hline AR798 & 9 & S of Marianna & Lee & 2004 & Unknown/Farmer's field \\
\hline AR800 & $?$ & S of Marianna & Lee & 2004 & Unknown/Farmer's field \\
\hline AR801 & $?$ & $\mathrm{~N}$ of Biscoe & Prairie & 2005 & Unknown/Farmer's field 1 \\
\hline AR803 & 7 & $\mathrm{~N}$ of Biscoe & Prairie & 2005 & Unknown/Farmer's field 1 \\
\hline AR805 & ? & $\mathrm{N}$ of Biscoe & Prairie & 2005 & Unknown/Farmer's field 1 \\
\hline AR807 & 7 & $\mathrm{~N}$ of Biscoe & Prairie & 2005 & Unknown/Farmer's field 2 \\
\hline AR808 & 9 & $\mathrm{~N}$ of Biscoe & Prairie & 2005 & Unknown/Farmer's field 2 \\
\hline AR809 & 15 & Pine Tree & St. Francis & 2005 & Asgrow A571 \\
\hline AR813 & ? & Pine Tree & St. Francis & 2005 & Triumph TR481 \\
\hline AR815 & 12 & Pine Tree & St. Francis & 2005 & Golden Acres 444E \\
\hline AR816 & 9 & Pine Tree & St. Francis & 2005 & Southern States SS-800 \\
\hline AR817 & ? & Pine Tree & St. Francis & 2005 & Terral TV9421 \\
\hline AR820 & $?$ & Pine Tree & St. Francis & 2005 & Terral TV96H81 \\
\hline AR825 & $?$ & Marianna & Lee & 2005 & Unknown/Filler row \\
\hline AR826 & 9 & Near Backgate & Desha & 2005 & Unknown/Farmer's field \\
\hline AR828 & 9 & Near Backgate & Desha & 2005 & Unknown/Farmer's field \\
\hline AR830 & 7 & Near Backgate & Desha & 2005 & Unknown/Farmer's field \\
\hline AR831 & $?$ & Marianna & Lee & 2005 & Monsanto MTC15525 \\
\hline AR834 & 8 & Marianna & Lee & 2005 & Southern States SS-650 \\
\hline AR837 & 19 & Marianna & Lee & 2005 & Terral TV93S72 \\
\hline AR838 & 16 & Marianna & Lee & 2005 & Pioneer 83G66 \\
\hline AR841 & ? & Marianna & Lee & 2005 & Triumph TR82-G \\
\hline
\end{tabular}


SC326-6, SC414-12E, BTX378, TAM428, TX2536, SC328C, QL3 (India), and BTX398.

Disease severity ratings were analyzed using the JMP statistical software package (SAS Institute, Cary, NC). Analyses of the disease severity ratings were conducted based on the locations where the isolates were collected, and three different splitplot analyses were performed. The main parameters used for these analyses were the year isolates were collected, the county in which isolates were collected, and the source in which isolates were collected. Source was used in these experiments to denote isolates collected from producer fields versus isolates collected from research stations. For each main parameter listed above, grain sorghum inbred lines (host differentials) were used as the split parameter. When interaction means were significant, least significant differences $(P$ $=0.05$ ) were calculated using the guidelines provided by Little and Hills (8). In the absence of significant interactions, the main effects were compared using the least squares means $t$ tests $(P=0.05)$.

\section{RESULTS}

Pathotype designation. Pathotypes 1 through 8 were previously described using C. sublineolum isolates from Texas, Georgia, and Puerto Rico (2). A summary of the reactions of the eight host differential sorghum inbred lines to the $C$. sublineolum isolates collected in Arkansas are presented in Table 2. Of the 98 isolates tested, only 87 isolates are reported here because reactions varied between MR and MS ratings (ability to sporulate on the host) on one or more of the host differentials between experiments for the other 11 isolates and, therefore, were excluded from further analysis. Among the remaining 87 isolates, we identified 13 pathotypes with $53 \%$ of the total samples evaluated being designated as pathotype 9 , which has not been previously reported. None of the isolates evaluated in these experiments were identified as pathotypes 1 through 6 . However, isolates representing pathotypes 7 and 8 , which had been previously reported (2), were found in Arkansas, as well as 11 new pathotypes (nos. 9, 10, 11, 12, 13, 14, 15, 16, 17, 18, and 19).

Five pathotypes were found from isolates collected from grain sorghum production fields in four different counties in Arkansas. More importantly, 10 of the 20 isolates evaluated from production fields were classified as pathotype 9 . In contrast, 12 pathotypes were discovered from isolates collected from research stations in Lee and St. Francis Counties. However, the majority of the isolates (35 of 67) evaluated from research stations were designated as pathotype 9 , which is similar to the results from isolates collected from grain sorghum production fields.

Anthracnose severity. There was a significant year of isolate collection-host differential interaction $(P=0.0001)$ and a significant interaction $(P=0.0226)$ for the county of isolate collection-host differential on disease severity (Table 3 ). No significant interactions $(P=0.7204)$ were observed for the source of isolate collection-host differential on disease severity (Table 3). There was a significant main effect from source (producer fields or research stations) on disease severity. Similarly, host differentials had a significant main effect on disease severity; however, variability between the inbred lines was

Table 3. Analysis of variance components including the degrees of freedom, sum of squares, $F$ ratio, and $P$ values for the effect of Colletotrichum sublineolum isolates collected by year, county, and from producer fields versus research stations on disease severity of eight grain sorghum host differentials ${ }^{y}$

\begin{tabular}{|c|c|c|c|c|}
\hline Source of variation ${ }^{z}$ & df & Sum of squares & $F$ ratio & $P$ value \\
\hline \multicolumn{5}{|l|}{ Year } \\
\hline Year & 2 & $135,968.18$ & $3,792.276$ & 0.0001 \\
\hline Host differential & 7 & $235,457.09$ & 137.032 & 0.0001 \\
\hline Year $\times$ host differential & 14 & $60,651.85$ & 17.649 & 0.0001 \\
\hline \multicolumn{5}{|l|}{ County } \\
\hline County & 3 & $2,606.46$ & 129.801 & 0.0001 \\
\hline Host differential & 7 & $187,056.07$ & 78.889 & 0.0001 \\
\hline County $\times$ host differential & 21 & $12,204.69$ & 1.716 & 0.0226 \\
\hline \multicolumn{5}{|l|}{ Location } \\
\hline Source & 1 & $1,938.99$ & 286.813 & 0.0035 \\
\hline Host differential & 7 & $24,0733.22$ & 100.842 & 0.0001 \\
\hline Source $\times$ host differential & 7 & $1,535.46$ & 0.643 & 0.7204 \\
\hline
\end{tabular}

${ }^{y}$ Isolates used in these experiments were collected in 2003, 2004, and 2005 within the state of Arkansas, from Desha, Lee, Prairie, and St. Francis Counties, two University of Arkansas research stations, and from different producer fields within the state. Disease severity ratings were collected 14 days after inoculation. Host differentials used in these experiments were SC326-6, SC414-12E, BTX378, TAM428, TX2536, SC328C, QL3 (India), and BTX398 (2).

${ }^{\mathrm{z}}$ Isolates were collected by year (Year) and county (County) and from producer fields and research stations (Location).

Table 2. Pathotype designation for 87 Colletotrichum sublineolum isolates collected in Arkansas based on virulence patterns for each isolate on eight grain sorghum host differentials

\begin{tabular}{|c|c|c|c|c|c|c|c|c|c|}
\hline \multirow[b]{2}{*}{ Pathotype } & \multirow[b]{2}{*}{ No. of isolates ${ }^{\mathrm{z}}$} & \multicolumn{8}{|c|}{ Differential line } \\
\hline & & SC326-6 & SC414-12E & BTX378 & TAM428 & TX2536 & SC328C & QL3 & BTX398 \\
\hline 1 & 0 & - & - & - & - & - & - & - & + \\
\hline 2 & 0 & - & - & - & - & - & - & + & + \\
\hline 3 & 0 & - & - & + & - & - & - & - & + \\
\hline 4 & 0 & - & - & - & + & + & + & - & + \\
\hline 5 & 0 & - & - & + & + & + & + & + & + \\
\hline 6 & 0 & - & + & + & + & + & + & + & + \\
\hline 7 & 13 & + & - & + & + & + & + & + & + \\
\hline 8 & 9 & + & + & - & + & + & + & + & + \\
\hline 9 & 46 & + & + & + & + & + & + & + & + \\
\hline 10 & 6 & + & + & - & + & + & - & + & + \\
\hline 11 & 4 & + & + & + & - & + & - & + & + \\
\hline 12 & 2 & + & + & - & - & + & + & + & + \\
\hline 13 & 1 & + & - & - & + & + & + & + & + \\
\hline 14 & 1 & + & + & - & - & + & - & + & + \\
\hline 15 & 1 & + & - & - & + & + & - & + & + \\
\hline 16 & 1 & + & - & - & + & + & + & - & + \\
\hline 17 & 1 & + & + & - & + & + & - & + & - \\
\hline 18 & 1 & + & - & - & + & + & - & - & + \\
\hline 19 & 1 & + & - & - & + & + & - & - & - \\
\hline
\end{tabular}

${ }^{\mathrm{z}}$ In all, 98 isolates were evaluated in these experiments. However, only 87 isolates are reported here because 11 isolates produced different reactions on some of the differentials between repetitions and therefore were excluded from further analysis. 
expected to have a significant influence on disease severity because some of the differential lines were resistant to some of the isolates. Therefore, the results on the effect of host differentials on disease severity pooled over both sources are not reported here.

Isolates collected in 2003 caused significantly higher levels of disease on the differential inbred line TX2536 than on SC326-6, SC414-12E, and BTX378 (Table $4)$. There were no significant differences for disease severity among differentials TAM428, TX2536, SC328C, QL3, and BTX398 from isolates collected in 2003. SC328C had significantly more disease than SC326-6, SC414-12E, and BTX378 for isolates collected in 2004 (Table 4). Similarly, no significant differences were detected for disease severity on TAM428, TX2536, SC328C, QL3, and BTX398 for the isolates collected in 2004. The results of testing isolates in the 2005 collection produced results similar to the 2003 and 2004 isolates. SC328C was more susceptible than SC326-6, SC414-12E, and BTX378 but there were no significant differences for TAM428, TX2536, SC328C, QL3, and BTX398 (Table 4).

There were significant interactions between the county from which the isolates were collected and the host differentials and there was a similar trend for the amount of disease on each host differential (Table 5). SC326-6 and SC414-12E were more resistant than TAM428 and SC328C for isolates from Desha and Prairie Counties. Numerically, the lowest level of disease was found on SC414-12E for all counties; the amount of disease on SC414$12 \mathrm{E}$ was not statistically different from SC326-6, BTX378, QL3, and BTX398 for isolates collected from Desha and Prairie Counties. There were no differences in disease severity on SC414-12E compared with SC326-6, BTX378, TAM428, QL3, and BTX398 for isolates collected in Lee and St. Francis Counties. When comparing the source (producer fields and research stations), isolates collected from research stations caused significantly more disease $(27.8 \%)$ than the isolates collected from producer fields $(25.6 \%)$ when pooled over all host differentials.

\section{DISCUSSION}

C. sublineolum isolates were collected in grain sorghum production areas from four counties located in the Mississippi River delta region of Arkansas to evaluate the pathogenic diversity of populations in Arkansas. The research reported here demonstrates that diversity, measured as differences in virulence, exists within the C. sublineolum populations in Arkansas. Based on virulence to eight host differential inbred sorghum lines, 11 new pathotypes were discovered in Arkansas in addition to the eight previously reported pathotypes (2,4). Pathotype diversity seemed to be more significantly associated with the year the isolates were collected than with the county from which the isolates were collected. In 2003, 10 of the 13 pathotypes reported in this work were discovered from the different isolate collection sites. In contrast, only 3 of the 13 pathotypes reported here were found in 2004, with isolates representing pathotype 9 being the dominant group.

Pathotype 9 isolates were the majority of isolates at all of our sampling sites in 2004. The source of initial inoculum was probably a mixture of many pathotypes that had previously been found at most of the sites in 2003. Previously, Li (7) showed that one $C$. sublineolum strain was detected at a higher frequency near the end of the growing season, although three strains were equally inoculated on the sorghum plants earlier in the growing season. Xia et al. (18) reported a similar situation with the rice blast pathogen Magnaporthe grisea and suggested that a founder effect and surrounding cultivars may have influenced the composition of populations within a susceptible field. Because our isolates were collected near the end of the growing season (after heading), we may have selected for individual isolates instead of multiple populations that could have been present during the earlier part of the growing season. However, isolates were found for pathotypes $13,14,15,16$,
17, 18, and 19, suggesting that smaller populations are still present from year to year but at a lower frequency. Previous research reported that $M$. grisea race recovery varied by cultivar, and several races could be recovered from one cultivar (3).

A larger number of pathotypes was found at research stations than in producer fields. One possible explanation for this outcome would be the differences in selection pressure between these two systems. For example, usually only one sorghum hybrid was planted in each producer's field whereas multiple hybrids were planted at research stations. Cardwell et al. (2) reported that care should be exercised because it is not known whether a complex of isolates persists in a population or whether these isolates are a threat outside of research stations. It has been suggested that sorghum cultivars should be thoroughly screened against the $C$. sublineolum races and pathotypes prevalent to an area before hybrids are released for largescale production (1).

The virulence of each isolate was determined by comparing susceptible reactions across different host differentials, but the level of disease varied between susceptible reactions. Nine sorghum isolates of $C$. sublineolum collected from different locations in India were grouped into three distinct aggressiveness categories based on the reactions of six susceptible genotypes

Table 4. Comparison of Colletotrichum sublineolum isolates collected in different years on the severity of sorghum anthracnose for eight sorghum host differentials

\begin{tabular}{lccc}
\hline & \multicolumn{3}{c}{ Disease severity $(\boldsymbol{\%})^{\mathbf{z}}$} \\
\cline { 2 - 4 } Host differential & $\mathbf{2 0 0 3}$ & $\mathbf{2 0 0 4}$ & $\mathbf{2 0 0 5}$ \\
\hline SC326-6 & $9.9 \mathrm{~b}$ & $16.5 \mathrm{~cd}$ & $11.2 \mathrm{abc}$ \\
SC414-12E & $8.5 \mathrm{~b}$ & $6.3 \mathrm{~d}$ & $4.6 \mathrm{c}$ \\
BTX378 & $8.9 \mathrm{~b}$ & $25.0 \mathrm{bcd}$ & $9.5 \mathrm{bc}$ \\
TAM428 & $22.8 \mathrm{ab}$ & $47.9 \mathrm{ab}$ & $31.4 \mathrm{ab}$ \\
TX2536 & $37.4 \mathrm{a}$ & $47.5 \mathrm{ab}$ & $24.7 \mathrm{abc}$ \\
SC328C & $20.6 \mathrm{ab}$ & $58.9 \mathrm{a}$ & $35.0 \mathrm{a}$ \\
QL3 (India) & $24.1 \mathrm{ab}$ & $41.6 \mathrm{abc}$ & $15.9 \mathrm{abc}$ \\
BTX398 & $23.3 \mathrm{ab}$ & $42.6 \mathrm{ab}$ & $21.2 \mathrm{abc}$ \\
\hline
\end{tabular}

z Values are the least squares means of all isolates collected in the designated year. Disease severity ratings were collected 14 days after inoculation, and means within the same year followed by the same letter are not significantly different $(P=0.05)$. Least significant difference $(0.05)$ to compare host differentials across years $=23.9$.

Table 5. Effect of Colletotrichum sublineolum isolates collected in different counties in Arkansas on the severity of sorghum anthracnose for eight sorghum host differentials

\begin{tabular}{lcccc}
\hline & \multicolumn{4}{c}{ Disease severity $(\boldsymbol{\%})^{\mathbf{z}}$} \\
\cline { 2 - 5 } Host differential & Desha & Lee & Prairie & St. Francis \\
\cline { 2 - 5 } SC326-6 & $11.8 \mathrm{bc}$ & $13.5 \mathrm{ab}$ & $13.6 \mathrm{bc}$ & $13.6 \mathrm{bc}$ \\
SC414-12E & $4.1 \mathrm{c}$ & $7.0 \mathrm{~b}$ & $5.2 \mathrm{c}$ & $6.9 \mathrm{c}$ \\
BTX378 & $18.5 \mathrm{abc}$ & $13.4 \mathrm{ab}$ & $16.0 \mathrm{bc}$ & $20.6 \mathrm{bc}$ \\
TAM428 & $44.6 \mathrm{a}$ & $33.6 \mathrm{ab}$ & $48.7 \mathrm{a}$ & $36.0 \mathrm{abc}$ \\
TX2536 & $36.7 \mathrm{ab}$ & $37.7 \mathrm{a}$ & $37.1 \mathrm{ab}$ & $42.4 \mathrm{ab}$ \\
SC328C & $42.3 \mathrm{a}$ & $40.0 \mathrm{a}$ & $49.8 \mathrm{a}$ & $43.9 \mathrm{a}$ \\
QL3 (India) & $30.0 \mathrm{abc}$ & $30.0 \mathrm{ab}$ & $21.9 \mathrm{abc}$ & $32.8 \mathrm{abc}$ \\
BTX398 & $25.6 \mathrm{abc}$ & $33.4 \mathrm{ab}$ & $34.5 \mathrm{abc}$ & $32.0 \mathrm{abc}$ \\
\hline
\end{tabular}

${ }^{z}$ Values are the least squares means of all isolates collected in the designated counties. Disease severity ratings were collected 14 days after inoculation, and means within the same county followed by the same letter are not significantly different $(P=0.05)$. Least significant difference $(0.05)$ to compare host differentials across counties $=27.9$. 
(10). In our experiments, we found two significant interactions. The first was for the year the isolates were collected and the host differential. The second was for the county from which isolates were collected by host differential on disease severity for the eight sorghum differential inbred lines previously used to describe pathotypes $(2,4)$. Isolates collected from the research stations tended to cause more disease than the isolates collected from producer fields when the data were pooled over all host differentials. All Arkansas isolates evaluated in these experiments were virulent to SC326-6 and TX2536 and more than 50\% of the isolates were virulent to all of the host differentials tested, suggesting that these inbred lines would not be good parents for breeding for anthracnose resistance in Arkansas.

Overall, our isolates caused the least amount of disease on SC326-6 and SC414$12 \mathrm{E}$. It was also noted that lesions formed only on the midvein of SC414-12E and not on the leaf lamina. This was not as evident for SC326-6; however, more lesions seemed to be on the midvein for this inbred line as well, although lesion numbers were not collected for these experiments. This type of infection could have a tremendous effect on the percentage of diseased area. The remaining six inbred lines had lesions on both the leaf lamina and midvein, producing more diseased area.

To our knowledge, the 11 new pathotypes identified in this study have not been previously reported using these host differentials. Isolates in pathotype 9 are virulent to all eight host differentials and comprised $53 \%$ of the total samples evaluated. More experiments are needed using different sorghum inbred lines to determine whether resistance exists for these isolates. If more inbred lines are incorporated into future pathotype experiments, then more pathotypes may be discovered within $C$. sublineolum populations found in Arkansas. In addition, more experiments are needed to evaluate the effect of pathotype 9 on commercial grain sorghum hybrids. This information should be useful to sorghum breeders and producers in order to effectively manage sorghum anthracnose in Arkansas.

\section{ACKNOWLEDGMENTS}

We thank the University of Arkansas, Division of Agriculture, and the Arkansas Corn and Grain Sorghum Research and Promotion Board for financial support of this research.

\section{LITERATURE CITED}

1. Ali, M. E. K., and Warren, H. L. 1987. Physiological races of Colletotrichum graminicola on sorghum. Plant Dis. 71:402-404.

2. Cardwell, K. F., Hepperly, P. R., and Frederiksen, R. A. 1989. Pathotypes of Colletotrichum graminicola and seed transmission of sorghum anthracnose. Plant Dis. 73:255-257.

3. Correa-Victoria, F. J., and Zeigler, R. S. 1993. Pathogenic variability in Pyricularia grisea at a rice blast "hot spot" breeding site in eastern Colombia. Plant Dis. 77:1029-1035.

4. Dale, J. L., Kirkpatrick, T. L., and Cardwell, K. F. 1988. Sorghum anthracnose in southwest Arkansas. Ark. Farm Res. 37(6): 17.

5. Frederiksen, R. A. 1986. Anthracnose Stalk Rot. Page 27 in: Compendium of Sorghum Diseases. R. A. Frederiksen, ed. American Phytopathological Society, St. Paul, MN.

6. Harris, H. B., Johnson, B. J., Dobson, J. W., and Luttrell, E. S. 1964. Evaluation of anthracnose on grain sorghum. Crop Sci. 4:460462.

7. Li, Y. 2004. Temporal and spatial development, relative fitness and dynamics of strains of $\mathrm{Col}$ letotrichum sublineolum on grain sorghum. Doctoral dissertation, University of Arkansas, Fayetteville.

8. Little, T. M., and Hills, F. J. 1978. Agricultural Experimentation Design and Analysis. John Wiley and Sons, Inc., New York.

9. Ngugi, H. K., Julian, A. M., King, S. B., and Peacocke, B. J. 2000. Epidemiology of sorghum anthracnose (Colletotrichum sublineo- lum) and leaf blight (Exserohilum turcicum) in Kenya. Plant Pathol. 49:129-140.

10. Pande, S., Mughogho, L. K., Bandyopadhyay, R., and Karunakar, R. I. 1991. Variation in pathogenicity and cultural characteristics of sorghum isolates of Colletotrichum graminicola in India. Plant Dis. 75:778-783.

11. Rosewich, U. L., Pettway, R. E., McDonald, B. A., Duncan, R. R., and Frederiksen, R. A. 1998. Genetic structure and temporal dynamics of a Colletotrichum graminicola population in a sorghum disease nursery. Phytopathology 88:1087-1093.

12. TeBeest, D., Kirkpatrick, T., and Cartwright, R. 2004. Common and important diseases of grain sorghum. In: Grain Sorghum Production Handbook. L. Espinoza and J. Kelly, eds. Univ. Ark. Coop. Ext. MP 297.

13. Thakur, R. P., and Mathur, K. 2000. Anthracnose. Pages 10-12 in: Compendium of Sorghum Diseases, Second Edition. R. A. Frederiksen and G. N. Odvody, eds. The American Phytopathological Society, St. Paul, Minnesota.

14. Thakur, R. P., Mathur, K., Rao, V. P., Chandra, S., Shivramkrishnan, S., Kannan, S., Hiremath, R. V., Tailor, H. C., Kushwaha, U. S., Dwivedi, R. R., and Indira, S. 1998. Pathogenic and genetic characterization of six Indian populations of Colletotrichum sublineolum, the causal agent of sorghum anthracnose. Indian Phytopathol. 51:338-348

15. Ware, S. B. 2001. Genetic diversity of Colletotrichum sublineolum based on vegetative compatibility, mtDNA and nuDNA restriction fragment length polymorphisms, and intron sequences. Masters thesis, University of Arkansas, Fayetteville.

16. Warren, H. L. 1986. Leaf Anthracnose. Pages 10-11 in: Compendium of Sorghum Diseases. R. A. Frederiksen, ed. American Phytopathological Society, St. Paul, MN.

17. Warren, H. L. 1986. Panicle and Grain Anthracnose. Page 40 in: Compendium of Sorghum Diseases. R. A. Frederiksen, ed. American Phytopathological Society, St. Paul, MN.

18. Xia, J. Q., Correll, J. C., Lee, F. N., Marchetti, M. A., and Rhoads, D. D. 1993. DNA fingerprinting to examine microgeographic variation in the Magnaporthe grisea (Pyricularia grisea) population in two rice fields in Arkansas. Phytopathology 83:1029-1035. 